\title{
DYNAMIC AND STATIC POSTURAL CONTROL IN VOLLEYBALL PLAYERS WITH TRANSFEMORAL AMPUTATION
}

\author{
CONTROLE POSTURAL DINÂMICO EESTÁTICO EM JOGADORES DEVÔLEI COM AMPUTAÇÃO \\ TRANSFEMORAL
}

\author{
CONTROL POSTURAL DINÁMICO Y ESTÁTICO DE JUGADORES DE VÓLEY CON AMPUTACIÓN \\ TRANSFEMORAL
}

\author{
Helmorany Nunes de Araújo \\ (Physiotherapist) \\ Felipe Augusto dos Santos Mendes² \\ (Physiotherapist) \\ Caroline Echavarria Fortes ${ }^{1}$ \\ (Physiotherapist) \\ Gabriela Borin ${ }^{3}$ (Physiotherapist) \\ Patrícia Azevedo Garcia² \\ (Physiotherapist) \\ Osmair Gomes Macedo² \\ (Physiotherapist) \\ Vera Regina Fernandes da Silva \\ Marães $^{2}$ (Physiotherapist) \\ Joao Luiz Quagliotti Durigan² \\ (Physiotherapist) \\ 1. Universidade de Brasília, Distrito \\ Federal, DF, Brazil. \\ 2. Universidade de Brasília, Physical \\ Therapy Division, Distrito Federal, \\ Brazil. \\ 3. University of Massachusetts, \\ Physical Therapy Division, \\ Department of Kinesiology, \\ Amherst, Massachusetts, USA.
}

\section{Correspondence:}

Helmorany Nunes de Araújo, Universidade de Brasília,

Faculdade de Ceilândia, Centro Metropolitano, conjunto A, lote 01 , Brasília, DF, Brazil. 72220-900.

helmo.nunes@gmail.com

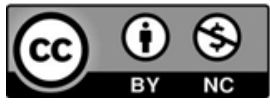

Original Article Artigo Original Artículo Original

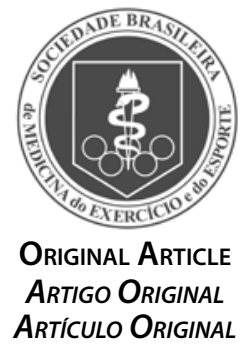

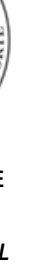


amputados con amputación transfemoral unilateral (grupo amputado: edad: $33,5 \pm 5,6$ años, peso: $77,7 \pm 5,3 \mathrm{~kg}$, altura: 179,4 $\pm 5,3 \mathrm{~cm}$ ) y ocho eran físicamente activos no amputados (edad del grupo control: $27,2 \pm 8,4$ años, peso: $82,7 \pm 6,6 \mathrm{~kg}$, altura: $178,7 \pm 6,1 \mathrm{~cm}$ ). El control postural estático y dinámico fue evaluado usando la plataforma Neuro$\mathrm{com}^{\circledR}$ Balance Master System (Test Clínico Modificado de Interacción Sensorial en el Equilibrio, Límites de Estabilidad, Variación Rítmica de Carga, Sentado para de pie, Marcha en la Plataforma y Paso con Inversión Rápida). Los análisis estadísticos fueron realizados con el test Shapiro-Wilk, el test de Levene y el test t de Student para muestras pareadas $(p<0,05)$. Resultados: El grupo de amputados demostró compromiso del control postural en todos los tests cuando comparado al grupo control $(p<0,05)$ en todos los tests posturales, con excepción de los tests de variación rítmica y sit-to-stand $(p>0,05)$. Conclusión: A pesar del entrenamiento en el vóley sentado, nuestros resultados demostraron que los amputados presentan un control postural más precario tanto en tareas estáticas como dinámicas, cuando comparados con los no amputados físicamente activos. Nivel de Evidencia ll; Estudio pronóstico - investigar el efecto de la característica del paciente en el resultado de una enfermedad/Estudio Retrospectivo.

Descriptores: Amputados; Balance postural; Deportes.

\section{INTRODUCTION}

A decrease in postural control and proprioception is a common result of lower-limb amputations. Proprioceptive afferents from the ankle, knee, and cutaneous inputs from the plantar soles play key roles in adjusting the upright human stance and gait. ${ }^{1,2}$ Due to the absent limb affecting the range of displacement, new movement patterns and visual feedback are essential to preserve postural control. ${ }^{3}$ Nevertheless, most amputees with satisfactory muscle strength who attend a rehabilitation program can almost completely regain their functional independence by using a prosthetic device., , $^{3,4}$

Sports and physical activity may improve physical function and overall quality of life in lower limb amputees. ${ }^{5}$ Practicing sitting volleyball, in general requires increased upper and lower limb muscular strength, endurance, power, and postural control. Sitting volleyball players need good conditioning, muscle strength, coordination of the extremities, and good postural control to be competitive., ${ }^{4,6}$ However, the mechanism of postural control adaptation in sitting volleyball amputees is unknown.

Previous studies ${ }^{7}$ showed that amputees were impaired in many aspects of postural control has evaluated static postural control in amputee (transfemoral and transtibial amputation) and non-amputee subjects with biometric photogrammetry. It was found that transtibial amputees presented significant lateral oscillation, while transfemoral amputees presented greater anteroposterior oscillation, compared to the control group. Authors ${ }^{8}$ described these findings as an inability to transfer power the prosthetic leg. In addition, some researchs ${ }^{9}$ showed that transtibial amputees presented poorer directional control and were slower to move their center of gravity (COG) than the control group. These findings are in agreement with the review ${ }^{3}$ which demonstrated that amputees had dynamic postural control impairments in the majority of the reviewed studies.

To date, there is no documentation of the static and dynamic postural control in amputees that are also active sitting volleyball players. Based on these previous studies, we hypothesized that the amputee group would present impaired static and dynamic postural control when compared to able-bodied subjects. Therefore, the objective of this cross-sectional controlled study was to compare the static and dynamic postural control of amputees that participated in sitting volleyball with able-bodied subjects. The information about how postural control is affect in this population could help clinicians to include specific balance training, focused on static or dynamic tasks, applied to sitting volleyball practice.

\section{METHODS}

\section{Study design}

This cross-sectional controlled study was designed and approved by the Ethics Committee of the School of Health Sciences at the University of Brasília (UnB) (N11911/12).

\section{Subjects}

The sample was recruited for convenience.Sample size was determined a priori using $\mathrm{G}^{*}$ Power (version 3.1.3; University of Trier, Trier, Germany) ${ }^{10}$ with the level of significance set at $p=0.05$ and power $(1-\beta)$ $=0.805$ in order to detect a large effect $\left(f^{2}>0.47\right)$. We conducted a pilot study with 5 amputee subjects in each group to evaluate the effect size for the main dependent variable (static and dynamic postural control). Based on these a priori calculations and the pilot study, the final sample size was selected.

Participated in this study eight amputees with unilateral transfemoral amputation, sitting volleyball athletes who have played for a minimum of 5 years with amputation caused by trauma or neoplasia who have adapted to the use of a suitable prosthesis (11.7 \pm 2 years). Subjects in this group were excluded if they had prior neuromuscular disorders and/or vascular impairments, or if they were adapting to a new prosthesis. All the amputees practiced sitting volleyball as a part of the Association of Special Physical Education Training Center (CETEFE) in Brasília, Brazil. The control group included eigth able-bodied subjects (non-amputee) who were physically active (performed activities such as volleyball, resistance training and running). Subjects self-reported activity levels using the International Physical Activity Questionnaire (IPAQ). Participants reported vigorous aerobic-type exercise for at least 20 minutes three or more times per week, moderate-intensity activity five or more times per week, or walking at least 30 minutes per day. All subjects signed the informed consent form.

The evaluation of the postural control of all subjects was conducted at the Movement Analysis Laboratory of the Physical Therapy Course of the University of Brasilia.

\section{Experimental procedure}

The subjects were evaluated using the Balance Master System (BMS) (Neurocom International, Inc Clackamas, OR, USA), with version 8.2 operating software. The BMS allows evaluation of various tasks involving postural control by providing visual feedback to the participant. The equipment consists of two platforms $(140 \mathrm{~cm} \times 43 \mathrm{~cm}$ ) connected, with four load sensors placed at the end of each platform to detect pressure. The platforms had a interface with a monitor set at eye level. 
The BMS provided the vertical forces detected on the platform in the anterior-posterior and medial-lateral directions as well as combined directions. A computer recorded the data measurements, analyzed the information, and generated a printed report.

\section{Static postural control test}

Modified Clinical Test of Sensory Interaction on Balance (mCTSIB) - This test assessed the oscillation speed (degrees per second) of the subject's center of gravity while standing in double support. The subjects position their feet, in accordance to the instructions on the screen, for 10 seconds, under four conditions: eyes open on stable surface, eyes closed on a stable surface, eyes open on an unstable surface and eyes closed on an unstable surface.

\section{Dynamic postural control tests}

Limits of stability (LOS): This test assessed the maximum distance that the subject could shift their center of gravity without moving their feet while maintaining stability. The subjects were instructed to move as quickly and precisely as possible towards each of the eight targets presented on the screen in front of them. Other measures assessed during this test included: reaction time, movement speed, maximum excursion and directional control. Rhythmic Weight Shift (RWS): Quantifies the subject's ability to rhythmically move their center of gravity (COG) from left to right and forward to backward between two targets at three distinct speeds: slow, medium and fast. The measured parameter was the on-axis COG velocity.Sit-to-Stand (STS): evaluates the subject's time to go from sitting to standing position in one single repetition. The measured parameters were weight transfer time and COG sway velocity. Walk Across (WA): Quantifies gait characteristics: width and step length, average gait speed and symmetry of pace length. The subjects were instructed to cross the platform with, at least, two steps. Measured parameters were average step length and speed. Step/Quick Turn test (SQT): Measures stability during 180 degrees $\left(^{\circ}\right)$ turn, which quantified stated time and oscillation of the center of gravity during the rotation. The SQT required the subject take two step forward, turn $180^{\circ}$ to left or right and then return to the starting position. The variables were turn time and turn sway.

The subjects performed all tests on the same day, each test was performed three times and the mean values obtained in each trial were recorded.

\section{Statistical analysis}

All values were reported as mean \pm SD. We used parametric tests given that the data were normally distributed (Shapiro-Wilk test) and had homogeneous variances (Levene's test). Student's t-Tests (independent samples) were conducted for all variables. All statistical analysis were performed using SPSS (IBM Corp. Released 2012. IBM Statistics for Windows, Version 21.0. Armonk, NY: IBM Corp.). An $\alpha$ value of 0.05 was used in all statistical evaluations. The effect sizes $(d)$ and power of the analyzes were calculated using G.Power 3.1.9.2.

\section{RESULTS}

Sixteen individuals were assessed for eligibility, eight amputees (8 male, age: $33.5 \pm 5.6$ years old, weight: $77.7 \pm 5.3 \mathrm{Kg}$, height: $179.4 \pm 5.3$ $\mathrm{cm}$ ) and eight controls (8 male, age: $27.2 \pm 8.4$ years old, weight: 82.7 $\pm 6.6 \mathrm{Kg}$, height: $178.7 \pm 6.1 \mathrm{~cm})$. There were no differences $(p>0.05)$ between age, height and weight of the amputee and control groups.

\section{Static postural control}

During the stable and unstable surface test with open eyes and with the eyes closed (mCTSIB), the amputee group presented increased sway velocity of the center of gravity $(p<0.05)$ compared to the control group (Figure 1).

\section{Dynamic postural control}

The results of WA and STS tests are presented in figure 2 ( $A$ and $B$ ), respectively. In the WA test, amputee group showed smaller average step length $(54.2 \pm 7.62 \mathrm{~cm})$ compared to control group $(79.2 \pm 8.7 \mathrm{~cm})$ and slower walking speed $(59.3 \pm 11.09 \mathrm{~cm} / \mathrm{s})$ compared to control group $(76 \pm 11.1 \mathrm{~cm} / \mathrm{s})$, both differences statistically significant $(p<.05)$ and with power of $99.9 \%$ and $80 \%$, respectively..

In the STS test, the weight transfer control values of the amputee group $(0.42 \pm 0.28 \mathrm{sec})$ were not significantly different from the control group $(0.5 \pm 0.2 \mathrm{sec})(\mathrm{p}>.05$; power $=9 \%)$. The amputee group also showed significative increased COG sway velocity $(6 \pm 1 \% \mathrm{~s})$ compared to the nonamputee group $(3.1 \pm 1.1 \%$ s) $(p<0.05 ; d=2,76$ and power $=99,9 \%)$.

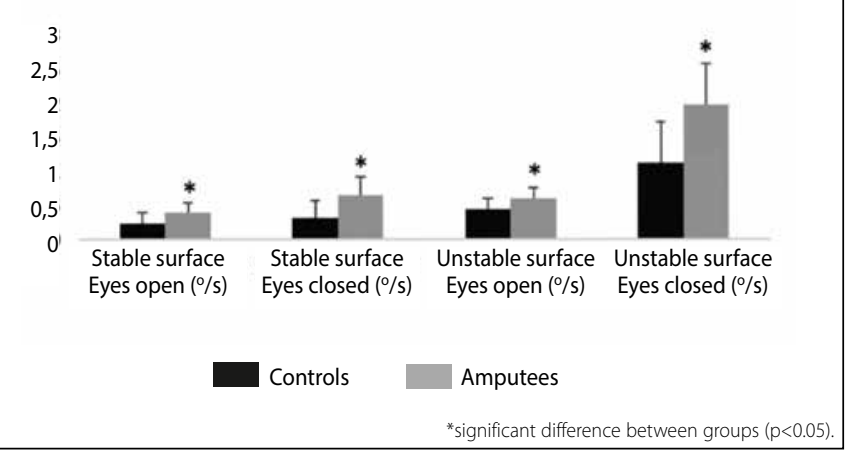

Figure 1. Static postural control speed oscilation (degrees/ seconds) results comparing controls and amputees in 4 situations. Error bars indicate standard deviations,

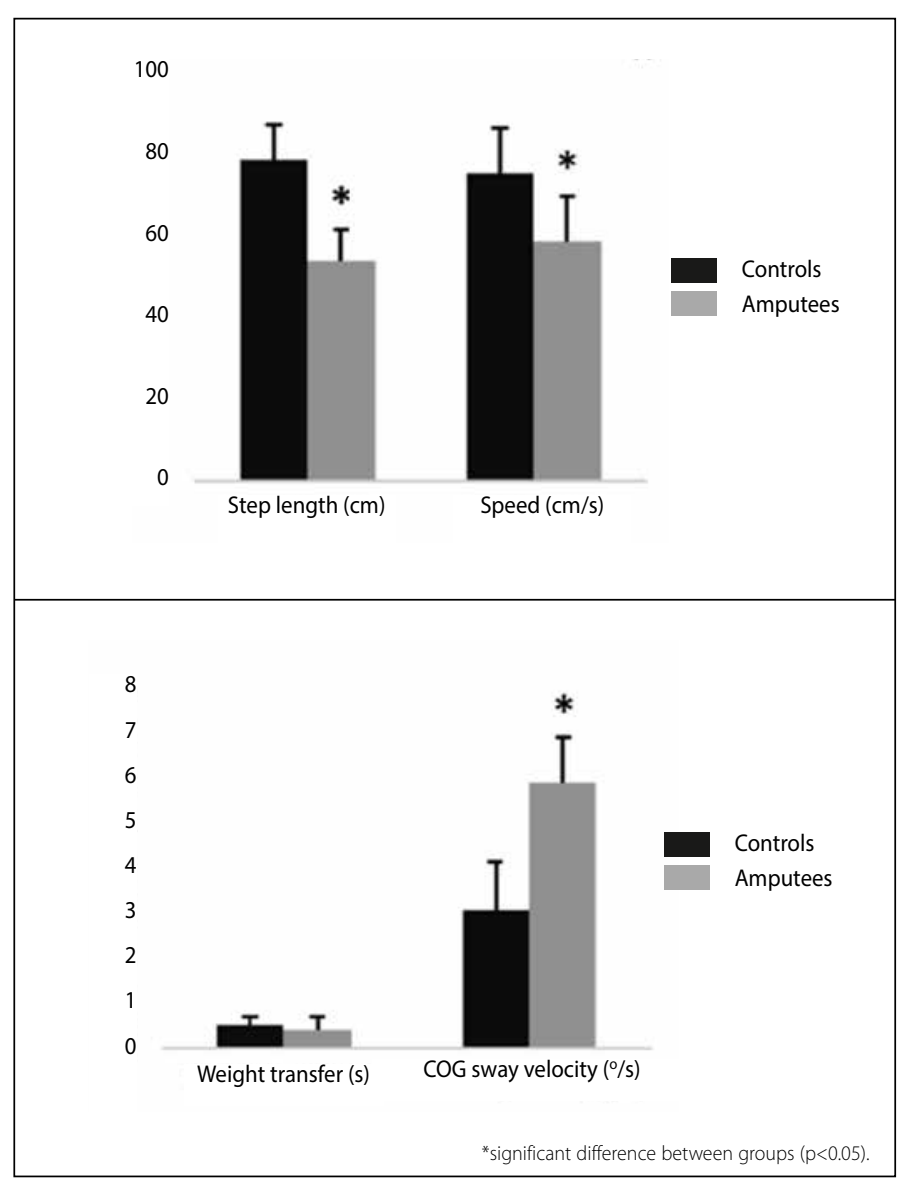

Figure 2. A) Walk Across test results comparing step length in centimeters $(\mathrm{cm})$ and gait speed in centimeters per seconds $(\mathrm{cm} / \mathrm{s})$. B) Sit-to-Stand test presented by weight transfer in seconds (s) and center of gravity sway velocity in degrees per seconds ( $\%$ s). Error bars indicate standard deviations. 
During RWS no significant difference was found ( $p>$.05) for speed of the movement on both axes (Table 1). LOS test showed significant difference between groups considering the reaction time variable, movement velocity and directional control $(p<.05)$. Amputee group also showed worst performance in SQT Test, demanding more execution time and a greater sway to turn $180^{\circ}$ both right and left side. The results of this dynamic test are presented in Table 1.

The results showed that the amputee group during the static and dynamic tests, had worse performance when compared to the control group, except for the tests RWS and STS.

Table 1. Values of dynamic tests Rythmic Weight Shift (RWS), Limits of Stability (LOS) and Step/Quick Turn (SQT).

\begin{tabular}{c|c|c|c|c}
\hline \multicolumn{7}{c}{ Dynamic Tests } \\
\hline Dynamic postural control & Controls & Amputees & Effectsize & Power \\
\hline Rhythmic Weight Shift (RWS) & & & & \\
\hline On-Axis Velocity Left/Right ( $\%$ /s) & $5.6 \pm 1.3$ & $5.56 \pm 1.1$ & 0.03 & $5 \%$ \\
\hline On-Axis Velocity Front/Back ( $\%$ s) & $3.5 \pm 0.7$ & $3.1 \pm 0.5$ & 0.65 & $23 \%$ \\
\hline Limits of Stability (LOS) & & & & \\
\hline Reaction Time (s) & $0.57 \pm 0.11$ & $0.81 \pm 0.1^{*}$ & 2.28 & $98.8 \%$ \\
\hline Movement Velocity ( $/$ s) & $5.6 \pm 1.1$ & $3.2 \pm 1.2^{*}$ & 2.08 & $97 \%$ \\
\hline Directional Control (\%) & $71.16 \pm 5.9$ & $63.3 \pm 6.1^{*}$ & 1.31 & $68 \%$ \\
\hline Step/QuickTurn (SQT) & & & & \\
\hline Turn Time Left Side (s) & $1.07 \pm 0.4$ & $2.25 \pm 0.42^{*}$ & 2.88 & $99.9 \%$ \\
\hline Turn Sway Left Side ( $\left.{ }^{\circ}\right)$ & $24.1 \pm 8.4$ & $39.5 \pm 4.2^{*}$ & 2.32 & $99 \%$ \\
\hline Turn Time Right Side (s) & $1.01 \pm 0.3$ & $2.34 \pm 0.39^{*}$ & 3.82 & $99.9 \%$ \\
\hline Turn Sway Right Side ( $\left.{ }^{\circ}\right)$ & $25.4 \pm 7.5$ & $46.6 \pm 4.7^{*}$ & 3.39 & $99.9 \%$ \\
\hline Values are reported as mean $\left( \pm\right.$ SD). ${ }^{*}$ Indicates a significant difference (P<0.05).
\end{tabular}

\section{DISCUSSION}

To our knowledge, this is the first demonstration of static and dynamic postural control in amputees volleyball players sitting. Confirming our initial hypothesis, our results clearly demonstrate that amputees present deficits in postural control compared to the able-bodied subjects. In both static and dynamic tests, subjects in the amputees group demonstrated greater impairment compared to the control group.

The static postural test results are in line with some studies, ${ }^{7,11}$ who also evaluated the static postural control of lower limb amputees compared with able-bodied subjects, and showed that amputees had worse postural control. However, most studies were conducted with amputees with different anatomical amputation levels (transtibial) or evaluated static postural control alone. The dynamic tests showed deficits in the postural control of the amputee group compared to the control group, which may result from the combination of two factors: 1) the absence of the proprioceptive inputs from the knee and ankle and, 2) the specificity of the sport activity. Sitting volleyball training emphasizes movement of the trunk and the proximal region of the lower limbs ${ }^{12}$ while many functional tasks, as tested in this study, require distal movement of the ankles and knees. Therefore, it seems that the practice of the sport alone is insufficient to promote proper postural control maintenance in lower limb amputee subjects.

There were only two tests that showed no significant difference between groups: RWS and STS. Although the RWS and the LOS are dynamic tests, the LOS test resulted in a poorer performance from the amputee group. This difference may be due to the LOS parameter being measured as an average of eight different speeds and directions, including diagonal movements. On the other hand, the RWS test is measured only by motion velocities in the two aforementioned directions. There is a significant probability that the difference in movement speed demonstrated between study groups in the LOS test was not due to the inability to generate rapid movements, but due to the difficulty of controlling movements performed in diagonal patterns and the difficulty of managing new anticipatory adjustments. These movements require greater muscle coordination to compensate for the rotational perturbations induced by the neuromotor asymmetry caused by the loss of the lower limb.2

The STS test evaluated the time required to voluntarily move the COG forward, starting and ending in a sitting position with the weight transferred completely on the feet. This parameter was not impaired in the amputee group in comparison to the control group, because the satisfactory performance on this test requires a rapid COG movement forward, which can be obtained by a rapid and controlled movement of the trunk. This ability is likely well developed in sitting volleyball as the trunk will play a major role in that specific athletic performance by taking over many of the functions of the lower limbs, transferring force to the upper limbs, and maintaining postural control during athletictraining. ${ }^{12}$

Previous studies have shown that individuals with lower limb amputation with a sedentary lifestyle had a balance deficiency compared to non-amputees. This might be related to greater reliance on visual information, and the decreased availability of proprioceptive information to control posture after amputation. ${ }^{7}$ Despite this information, studies comparing the postural control of amputee athletes with physically active able-bodied subjects are scarce, and the few studies found, did not mention if the controls were sedentary or physically active. This information is important because it is well established that physical activity can modify many parameters, including postural control. ${ }^{13}$ Addressing this issue, our study compared amputee athletes to physically active able-bodied subjects, which may have resulted in a greater difference in postural control variables between groups.

The most commonly practiced sports amongst lower-limb amputees are swimming, gymnastics, cycling and walking. ${ }^{14}$ We only found two studies that discuss the postural control of soccer players who were below-knee amputees with crutches, the athletes showed better postural control compared to the sedentary group. ${ }^{4}$ Another study comparing static and dynamic postural control in amputee soccer players compared to non-amputee subjects, found that the amputee soccer players also presented postural instability as a direct result of amputation and not simply as a result of physical inactivity. ${ }^{4,15}$

Finally, we believe that amputees should be encouraged to take part in sports given their importance to wellness and quality of life. Our results emphasize an important issue related to sports practice among amputees, which is that the postural control deficit is not completely resolved by enhancing balance. We observed that during the performance of RWS, which had similar demands to sitting volleyball, like moving their center of gravity in different directions, the amputee group showed similar results to the control group. Some limitations of this study include the lack of homogeneity of the amputee group considering the type, time of use, and adaptation to the prosthesis. Also, this study focused on static and dynamic postural control at the orthostatic position, future studies must add evaluations concerning sitting balance because of its relevance to the sport investigated by the study.

It appears that the practice of the sport itself cannot solve the existing postural control deficits. Further balance practice of performing volitional postural movements, for example using low-cost gaming tools, may improve balance ability and postural control in these patients. Additional studies are necessary for possible generalization, especially those that compared the effects of a specific postural control and proprioceptive training program to the routine of sedentary and athletes with transfemoral amputations. 


\section{CONCLUSIONS}

Our results clearly demonstrated that sitting volleyball players who are amputees presented poorer static and dynamic postural control during balance tasks compared to physically active non-amputees. No differences were observed in amputees compared to controls for two tests, STS and RWS, which are correlated with skills required for sitting volleyball practice. Balance training, including static and dynamic postural control tasks, should be considered into the physical preparation routine of sitting volleyball amputees athletes.

All authors declare no potential conflict of interest related to this article

AUTHORS' CONTRIBUTIONS: Each author made significant individual contributions to this manuscript. HNA (0000-0002-2975-5752)*: data collection and writing of the article; FASM (0000-0002-2058-7481)*: statistical data analysis and revision of the article; CEF (0000-0002-2406-4768)*: writing and revision of the article; GB (0000-0003-4460-4546)* translation into English and revision of the article; PAG (0000-0002-9043-1386)*: data collection and revision of the article; OGM (0000-0002-1842-3410)*: statistical data analysis and revision of the article; VRFSM (0000-0002-8895-9624)*: intellectual concept of the article and drafting of the research project; LLD (0000-0002-7511-5289)*: revision of the article and data analysis. ${ }^{*} \mathrm{ORCID}$ (Open Researcher and Contributor ID).

\section{REFERENCES}

1. Kavounoudias A, Tremblay C, Gravel D, lancu A, Forget R. Bilateral changes in somatosensory sensibility after unilateral below-knee amputation. Arch Phys Med Rehabil. 2005;86(4):633-40.

2. Aruin AS, Nicholas JJ, Latash ML. Antecipatory postural adjustments during standing in below-the-knee amputees. Clin Biomech.1997;12(1):52-9.

3. Ku PX, Abu Osman NA, Wan Abas WAB. Balance control in lower extremity amputees during quiet standing: A systematic review. Gait Posture. 2014;39(2):672-82.

4. Yazicioglu K, Taskaynatan MA, Guzelkucuk U, Tugcu I. Effect of playing football (soccer) on balance, strength, and quality of life in unilateral below-knee amputees. Am J Phys Med Rehabil. 2007;86(10):800-5

5. Bragaru M, Dekker R, Geertzen JHB, Dijkstra PU. Amputees and sports: A systematic review. Sport Med 2011;41(9):721-40.

6. Alguacil IM, Molina F, Gómez M. Impact of exercise on the amputee. Arch Med del Deport 2010;27(138):291-302

7. Baraúna M, Duarte F, Sanchez H, Canto RST, Malusá S, Campelo-Silva CD, et al. Evaluation of the Static Balance Lower Limb Amputeers by Means of Computerized. Rev Bras fisioter. 2006;10(1):83-90.

8. Bolger $\mathrm{D}$, Ting LH, Sawers A. Individuals with transtibial limb loss use interlimb force asymmetries to maintain multi-directional reactive balance control. Clin Biomech. 2014:29(9):1039-47.

9. Vrieling $\mathrm{AH}$, van Keeken $\mathrm{HG}$, Schoppen T, Otten E, Hof AL, Halbertsma JP, et al. Balance control on a moving platform in unilateral lower limb amputees. Gait Posture. 2008;28(2):222-8.

10. Faul F, Erdfelder E, Buchner A, Lang AG. Statistical power analyses using G*Power 3.1: tests for correlation and regression analyses. Behav Res Methods. 2009;41(4):1149-60

11. Buckley J, O'Driscoll D, Bennett S. Postural sway and active balance performance in highly active lower-limb amputees. Am J Phys Med Rehabil. 2002;81(1):13-24.

12. Carvalho C, Gorla J, Araújo P. Sitting Volleyball: the knowledge to initiation of practice. Conex Rev da Fac Educ Física da UNICAMP. 2013;11(2):97-126.

13. Perrin PP, Gauchard GC, Perrot C, Jeandel C. Effects of physical and sporting activities on balance control in elderly people. Br J Sports Med. 1999;33(2):121-6.

14. Bragaru M, Meulenbelt HEJ, Dijkstra PU, Geertzen JH, Dekker R. Sports participation of Dutch lower limb amputees. Prosthet. Prosthet Orthot Int. 2013;37(6):454-8.

15. Kars C, Hofman M, Geertzen JHB, Pepping GJ, Dekker R. Participation in sports by lower limb amputees in the Province of Drenthe, The Netherlands. Prosthet Orthot Int. 2009;33(4):356-67. 